\title{
Range Extension of the \\ Satpura Leopard Gecko, Eublepharis satpuraensis (Squamata: Eublepharidae), from Jashpur District, Chhattisgarh, India
}

\author{
Ravi Naidu ${ }^{1}$, Krunal Trivedi ${ }^{2}$, Ameet Mandavia ${ }^{1}$, Rohit K Kalyari ${ }^{3}$, Saurabh Singh ${ }^{3}$, and Ashwini Chouhan ${ }^{3}$ \\ ${ }^{1}$ Conservation \& Research of Wilderness Foundation, Jagdalpur, Bastar, Chhattisgarh 494001, India \\ ${ }^{2}$ Nature Club Surat, Parle Point, Surat, Gujarat 395007, India (krunal.trivedi.7567@gmail.com) \\ ${ }^{3}$ Jashpur Wildlife Welfare Foundation, Jashpur Nagar, Chhattisgarh 496331, India
}

Photographs by the senior author.

Cour species of leopard geckos in the genus Eublepharis, the Common Leopard Gecko (E. macularius), Western Indian Leopard Gecko (E. fuscus), Eastern Indian Leopard Gecko (E. hardwickii), and the Satpura Leopard Gecko (E. satpuraensis), occur in India (Grismer 1988; Uetz et al. 2020). Mirza et al. (2014) described the range of the Satpura Leopard Gecko as the Satpura Hills, including Panchmari and the surrounding areas of the Satpura Tiger Reserve, Bhopal, the Melghat Tiger Reserve, the Pench Tiger Reserve, the Bandhavgarh Tiger Reserve, and Jabalpur in central India. Basak et al. (2017) subsequently reported this species from the Bhormadeo Wildlife Sanctuary and adjacent areas in Chhattisgarh. Herein we report the presence of the species in Jashpur District, Chhattisgarh.

At $0020 \mathrm{~h}$ on 20 May 2020, during a faunal survey of Jashpur District, we found a juvenile E. satpuraensis (Fig. 1) near the Kailash Gufha Road $\left(23^{\circ} 03^{\prime} 53.13^{\prime N}\right.$, $83^{\circ} 33^{\prime} 26.79^{\prime \prime E)}$. At $0115 \mathrm{~h}$ the next day, we found an adult (Fig. 2) near Madheshwar Mountain (22 48'05.93"N,

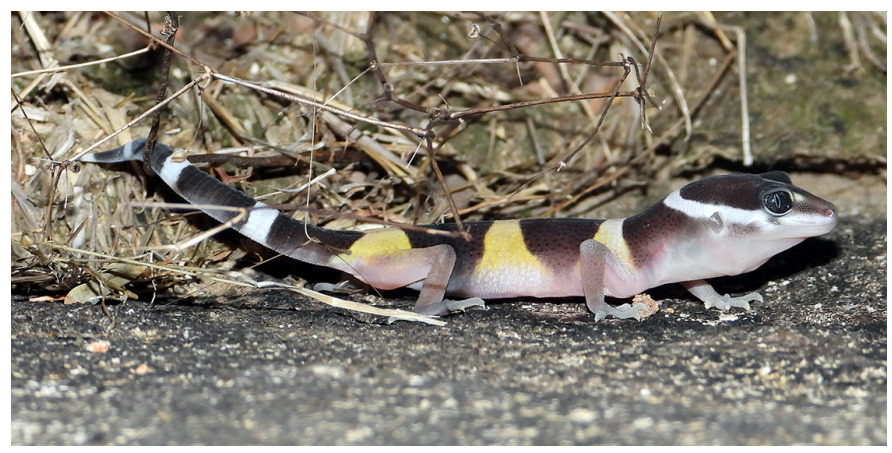

Fig. 1. A juvenile Satpura Leopard Gecko (Eublepharis satpuraensis) from near the Kailash Gufha Road, Jashpur District, Chhattisgarh, India. $84^{\circ} 02^{\prime} 40.05^{\prime \prime E}$ ). These sites are approximately $300 \mathrm{~km}$ from the nearest previously known locality in the Bhoramdeo Wildlife Sanctuary. We identified the species using the key in Mirza et al. (2014). Both geckos were in rocky habitat and released after we took photographs. Extensive habitat destruction and mining in the area (Fig. 3) pose substantial threats to this population.

\section{Acknowledgments}

We thank Zeeshan A. Mirza and Krishnendu Basak for confirming the identity of the species. We also thank Nileshkumar Kshirsagar (IAS), Jadhav Shrikrishna (IFS), the Chhattisgarh Forest Department, and the Jashpur Wildlife Welfare Foundation for their support. Pravin Kumar Singh, Umesh Sahu, Samar Vijay Prasad, and several others helped in the field.

\section{Literature Cited}

Basak, K., M. Ahmed, M. Suraj, and K. Mondal. 2017. Satpura Leopard Gecko: Range extension record of a newly described species, Eublepharis satpuraensis

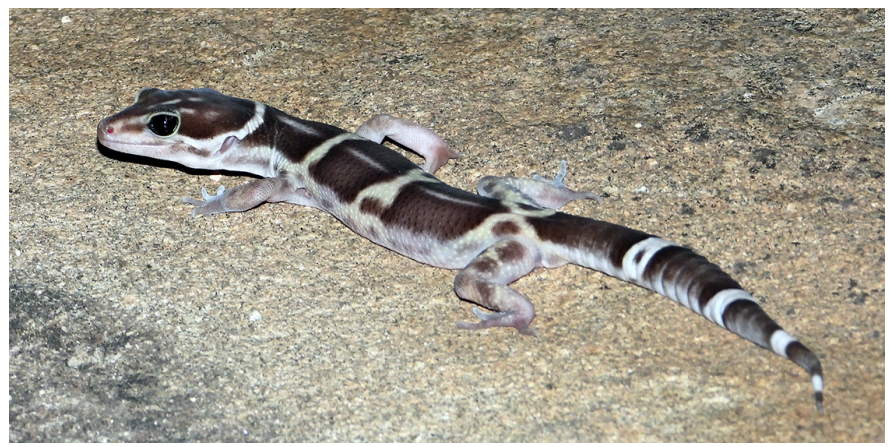

Fig. 2. An adult Satpura Leopard Gecko (Eublepharis satpuraensis) from Madheshwar Mountain, Jashpur District, Chhattisgarh, India. 


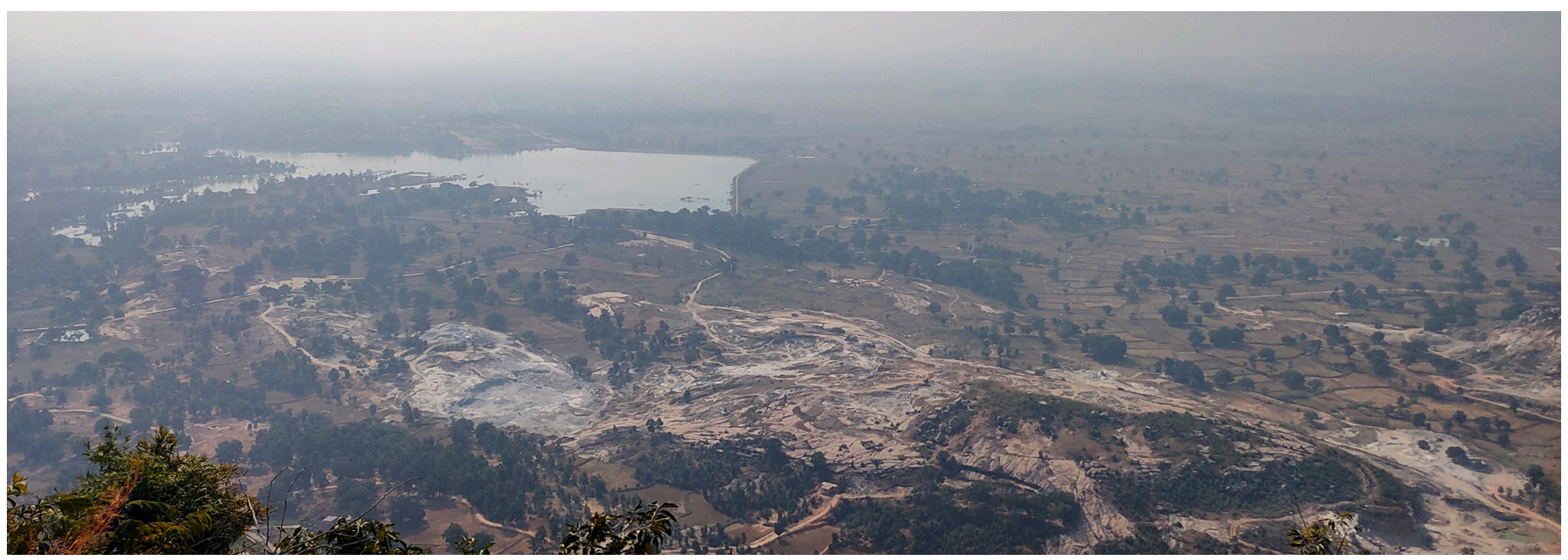

Fig. 3. Extensive mining in the Jashpur District, Chhattisgarh, India, poses a substantial threat to the local population of the Satpura Leopard Gecko (Eublepharis satpuraensis).

from Bhoramdeo Wildlife Sanctuary, Chhattisgarh, central India. Reptile Rap \#173. Zoos' Print Journal 32: 34-39.

Grismer, L.L. 1988. Phylogeny, taxonomy, classification, and biogeography of eublepharid geckos, pp. 369-469. In: R. Estes and G. Pregill (eds.), Phylogenetic Relationships of the Lizard Families. Essays Commemorating Charles L. Camp. Stanford University Press, Redwood City, California.
Mirza, A.Z., R.V. Sanap, D. Raju, A. Gawai, and P. Ghadekar. 2014. A new species of lizard of the genus Eublepharis (Squamata: Eublepharidae) from India. Phyllomedusa 13: 75-90.

Uetz, P., P. Freed, and J. Hošek (eds.). 2020. The Reptile Database. <http://www. reptile-database.org>. 